\title{
AVALIAÇÃO AMBIENTAL INTEGRADA DA MICROBACIA HIDROGRÁFICA DO CÓRREGO RIBEIRÃO BANDEIRANTES REBOJO NO MUNICÍPIO DE TARABAI - SP
}

Camila Dias Pinaffi'; Maira Braghin Christovam¹; Nayara Coelho Silva; ${ }^{1}$ Décio Lima de Vasconcelos Júnior ${ }^{2}$.

${ }^{1}$ Discente do Curso de Engenharia Ambiental da Faculdade de Engenharias da UNOESTE. ${ }^{2}$ Docente de Engenharia Ambiental - UNOESTE

\section{RESUMO}

O presente artigo visa avaliar a situação da microbacia do Córrego Ribeirão Bandeirantes Rebojo que está situada no município de Tarabai, SP. Para tal foram realizadas pesquisa de campo, consulta ao acervo da Prefeitura Municipal de Tarabai e entrevistas aos produtores, visando melhor compreender a organização social e o manejo de uso da terra das propriedades. Por meio do estudo realizado foi possível notar que antes da participação no Programa Estadual de Microbacias Hidrográficas a microbacia sofreu vários prejuízos ambientais, como a diminuição da biodiversidade, a erodibilidade e perda de fertilidade do solo, desunião dos produtores rurais e a alteração da qualidade e da dinâmica hídrica, aderindo ao programa foram feitas contenções nas erosões, maior interação dos produtores, proteção das nascentes, dentre outras iniciativas de proteção ao meio ambiente.

Palavras-chave: Sub-bacia Hidrográfica; Impactos Ambientais; Gestão sustentável.

\section{INTRODUÇÃO}

Ao longo do tempo o homem vem se utilizando dos recursos hídricos sem a preocupação de ver nestes um bem finito. A crescente demanda pelo uso dos recursos naturais foi acompanhada nas últimas décadas pela preocupação com a quantidade e qualidade desses recursos. Dessa forma, cresceu enormemente o valor da bacia hidrográfica como unidade de análise e planejamento ambiental (NASCIMENTO \& VILLAÇA, 2008).

O termo bacia hidrográfica refere-se a uma compartimentação geográfica natural delimitada por divisores de água, sendo este compartimento drenado superficialmente por um curso d'água principal e seus afluentes (SILVA, 1995). As bacias hidrográficas constituem ecossistemas adequados para avaliação dos impactos causados pela atividade antrópica que podem acarretar riscos ao equilíbrio e à manutenção da quantidade e a qualidade da água, uma vez que estas variáveis são relacionadas com o uso do solo (FERNANDES \& SILVA, 1994; BARUQUI \& FERNANDES, 1985).

A subdivisão de uma bacia hidrográfica de maior ordem em seus componentes (subbacias) permite a pontualização de problemas difusos, tornando mais fácil a identificação de focos de degradação de recursos naturais, da natureza dos processos de degradação ambiental 
instalados e o grau de comprometimento da produção sustentada existente (FERNANDES \& SILVA, 1994).

A gestão adequada de bacias hidrográficas necessita, antes de tudo, de um planejamento socioeconômico ambiental, a fim de buscar soluções que se enquadrem dentro dos limites da capacidade de suporte ambiental desta bacia. Assim, é importante a caracterização e o conhecimento da capacidade de suporte, dos riscos e impactos ambientais e dos objetivos de qualidade ambiental intrínseco às unidades socioeconômicas, tais como: comunidades, famílias rurais e produtores, inseridas na unidade biogeofísicas, que é a sub-bacia hidrográfica (ARAÚJO et al., 2009).

Nas etapas de planejamento e do gerenciamento de bacias hidrográficas é imprescindível que ocorra à participação e o envolvimento da comunidade, de maneira que esses usuários dos recursos naturais possam negociar e acatar as normas e diretrizes de uso, de conservação e desenvolvimento de seu território de forma sustentada. Nesse sentido, é fundamental que os usuários tenham conhecimento do ambiente que os envolvem, suas fragilidades e potencialidades, envolvendo assim os mecanismos de regulação do uso do solo e dos demais recursos naturais, evitando desta forma, os impactos ambientais na área da bacia hidrográfica (ARAÚJO et al., 2009).

As abordagens de planejamento e gestão que utilizam a bacia hidrográfica como unidade básica de trabalho, são mais adequadas para a compatibilização da produção com a preservação ambiental (SOUZA \& FERNANDES, 2010). Dessa maneira, torna-se fundamental estabelecer de forma sistematizada as principais fragilidades ambientais de uma sub-bacia hidrográfica, e apresentar medidas que compatibilize sua produção com a preservação ambiental, garantindo a sustentabilidade.

\section{OBJETIVO}

O presente estudo tem por objetivo avaliar de forma integrada os impactos ambientais evidenciados na Sub-bacia Hidrográfica do Córrego Ribeirão Bandeirantes Rebojo, localizada no município de Tarabai-SP, bem como apresentar soluções que priorizam o desenvolvimento sustentável da mesma. 


\section{MATERIAIS E MÉTODOS}

O presente artigo foi elaborado mediante uma visita in loco nas propriedades que pertencem a Bacia Hidrográfica localizada na cidade de Tarabai - SP, onde foi observada a situação atual de nascentes e dos cursos hídricos que regem a bacia, bem como pela consulta de dados cedidos pela Casa da Agricultura da cidade, entrevista aos produtores e pelo estudo bibliográfico de trabalhos científicos.

Desta maneira, foi realizada uma checagem nas propriedades rurais que abrangem nascentes, avaliando assim diversos pontos como, por exemplo, áreas de preservação permanente (APP), o tipo de cultura, cercas para proteger o leito dos cursos hídricos, além de verificar as condições das estradas que ligam a bacia, entre outros fatores. Deste modo, foram abordados os principais problemas que são enfrentados, buscando assim soluções para os mesmos de forma a promover o beneficiamento dos proprietários.

\section{RESULTADOS E DISCUSSÕES}

As propriedades visitadas se encontram no município de Tarabai - SP, e está localizado a sudoeste do Estado de São Paulo, nas seguintes coordenadas geográficas: 22ㅇ 18' Latitude Sul e 51ㅇ 32' Longitude Oeste, altitude 450 m, apresenta uma área de 202 km² e uma população de 6607 habitantes, sendo 6109 na área urbana e 498 na rural. A cidade pertence à Bacia Hidrográfica do Pontal do Paranapanema, sendo seu sistema de drenagem formado pelos Ribeirão Rebojo, Ribeirão Laranjeira e Rio Pirapozinho.

A microbacia possui uma área de 4.517 ha, suas estradas de acesso são: Estrada antiga Taquaruçu/Brasileira, Estrada Municipal Tarabai - Sandovalina, Estrada do Bairro Rebojo, Rodovia Assis Chateaubriand (SP 425), com uma distância de 5 km da sede, seus cursos d'água são Ribeirão Rebojo, córrego Bandeirantes, Santa Maria, Arca ou Coivara.

O uso do solo da microbacia está atualmente relacionado predominantemente à pecuária, sendo que a maior parte das áreas agricultáveis está coberta por pastagens em virtude do empobrecimento dos solos podzolizados. Visando a melhoria de seu rebanho, aos poucos os proprietários estão se conscientizando e tratando melhor o gado tanto o leiteiro como o de corte. Alguns tratam no cocho e outros através de suplementos (sal proteico, sal mineral), inclusive alguns adotam o sistema de adubação de pastagens e manejo adequado.

Há também, na maior parte das propriedades o plantio semestral, possuindo uma baixa produtividade e pouca lucratividade mediante a oscilação dos preços, a dificuldade no 
plantio devido ao solo possuir baixa fertilidade e ser ácido, além do fato de não conseguirem plantar em épocas diferentes por não possuírem um sistema de irrigação ou outro tipo de tecnologia mais avançada. Com o intuito de melhorar a qualidade da cultura e do plantio foram realizadas capacitações dos produtores em calagem e adubação, houve a busca por tecnologias mais adequadas para o sistema de plantio e palestras para os produtores para que assim possam gerir de maneira adequada seu sistema de cultivo.

Para conter os processos erosivos causados pela ausência de práticas conservacionistas de solo ou implantação de práticas inadequadas ao tipo de solo predominante e implantação de culturas não recomendadas com a capacidade de uso do solo, foram realizadas práticas de terraceamento, calagem, plantio direto e subsolagem.

A cobertura vegetal está presente em pequenas áreas de mata ciliar, com necessidade de recomposição para controlar o processo de assoreamento dos mananciais, havendo poucos animais silvestres atualmente. A intensiva utilização das terras acabou com a cobertura de florestas nativas, e com isso extinguiu a flora e fauna locais. Atualmente, os animais e aves mais encontrados na microbacia são: capivara, perdiz, codorna, quero-quero, lebres, maritacas, marrecos, garça carrapateira, cará-cará, urubu, entre outros.

Animais e aves que existiam na área da microbacia e hoje se encontram em extinção: siriema, nambú, papagaio, passo-preto, coleirinha do brejo, raposa, preás, lagartos, cotia, canário da terra, sabiá, furão, veado mateiro, gambá, lontra e algumas espécies de cobras que tantas, eram até capturadas e enviadas ao Instituto Butantã para fazer soro antiofídico. Em relação à fauna aquática, as espécies de peixes quase em extinção são: cascudos, curimbatá, piau, douradinho e outros. Em relação à flora, existem hoje poucas espécies como: angíco, ipê-tabaco, ipê-roxo, manguba, leiteiro, amendoim bravo, assapeixe, goiabeira, entre outras.

Os problemas ocasionados pela poluição são intensamente verificados no córrego, com redução da quantidade e qualidade da água utilizada na irrigação de lavouras e dessedentação de animais. Com o objetivo de amenizar esta problemática foram colocadas cercas para proteção das nascentes, houve a recomposição da mata ciliar dos mananciais e orientação sobre a importância da conservação ambiental para os produtores.

Em relação às estradas rurais da microbacia, foram desenvolvidos programas de adequação das mesmas, com captação de águas pluviais através de bacias e terraços nos últimos anos e o poder público municipal tem se esforçado no sentido de conservar totalmente as estradas da microbacia. 
Apesar do desestímulo em que se encontram boa parte dos agricultores, mediante a baixa produtividade das culturas, baixa produtividade agrícola, dificuldade de comercialização, o associativismo na microbacia tem despertado novamente o interesse quanto à necessidade de união e participação dos produtores para discussão dos problemas, em busca de soluções, como melhoria na qualidade de vida e valorização do homem do campo. Porém, os moradores encontram dificuldades devido à ausência de um espaço para uso comunitário que possibilitaria uma maior socialização da comunidade e realização de eventos culturais e de lazer.

\section{CONCLUSÃO}

A partir do momento que se iniciaram os trabalhos do Programa Estadual de Microbacias Hidrográficas junto aos produtores da microbacia do Córrego do Ribeirão Bandeirantes Rebojo, nota-se uma maior integração entre os produtores, buscando aumentar a qualidade não apenas de seu rebanho, mas de toda a propriedade, acarretando no aumento da qualidade do solo, adoção de medidas de proteção aos mananciais e nascentes, além de propiciar uma melhor estrutura para enfrentar as dificuldades encontradas no campo.

\section{REFERÊNCIAS}

ARAÚJO, L. E.; SOUSA, F. A. S.; NETO, J. M. M.; SOUTO, J. S.; REINALDO, L. R. L. R. Bacias hidrográficas e impactos ambientais. Qualitas Revista Eletrônica, Vol. 8, № 1, 2009.

BARUQUI, A. M.; FERNANDES, M. R. Práticas de conservação do solo. Belo Horizonte. Informe Agropecuário, Belo Horizonte. v. 11, n. 128. p. 55-69, ago. 1985.

FERNANDES, M.R.; SILVA, J. C. Programa Estadual de Manejo de Sub-Bacias Hidrográficas: Fundamentos e estratégias - Belo Horizonte: EMATERMG. 24p. 1994.

NASCIMENTO, W. M.; VILLAÇA, M. G. Bacias hidrográficas: planejamento e gerenciamento. Revista Eletrônica da Associação dos Geógrafos Brasileiros - Seção Três Lagoas, MS - № 7 - ano 5, Maio de 2008

SILVA, A. M. Princípios Básicos de Hidrologia. Departamento de Engenharia. UFLA. Lavras- MG. 1995.

SOUZA, E.R.; FERNANDES, M.R. Sub-bacias hidrográficas: unidades básicas para o planejamento e gestão sustentáveis das atividades rurais. Informe agropecuário. Belo Horizonte, v. 21, n. 207, p. 15-20. 2000. 